\title{
Hasta ve Sağlık Çalışanlarının, Hasta Hakları Konusunda Bilgi Düzeyleri: Bir Müdahale Çalışması
}

\author{
Knowledge Levels of Patıents and Health Staffs "Patıent Rights": \\ An Intervention Study
}

\section{Özgür Erdem', Hediye Seval Akgün²}

' Özgür Erdem, Sağlık Bakanlığı, Halk Sağlığı Genel Müdürlüğüu, Ankara

${ }^{2}$ Hediye Seval Akün Başkent Üniversitesi, Tıp Fakültesi, Ankara

Yazısma Adresi / Correspondence:

Özgür Erdem

T.C. Sağlık Bakanlığı, Halk Sağlığı Genel Müdürlüğü, Ankara

T: +90 5365749489 E-mail: ozgurerdem1977@gmail.com

Geliş Tarihi / Received : 27.07.2018 Kabul Tarihi / Accepted : 05.08.2018

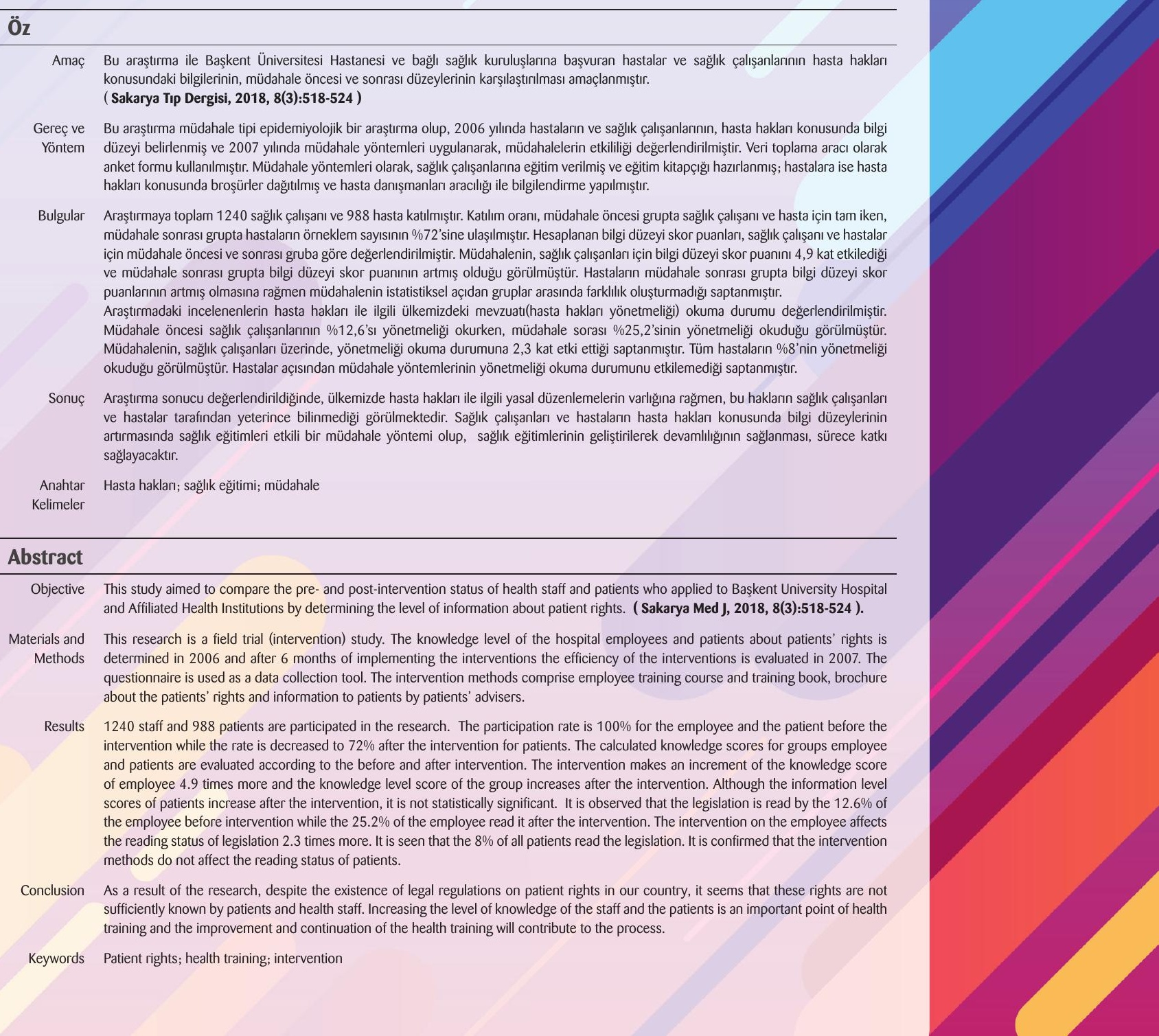


Sakarya Tip Dergisi

2018;8(3):518-524

ERDEM ve Ark.

Hasta ve Sağlık Çalişanlarının, Hasta Hakları

\section{Giriş}

İnsanoğlunun hak ve özgürlük uğruna verdiği mücadele, siyasal toplum öncesi, doğal toplum ortamında bulundukları dönemde dahi var olmuş ve devlet adı verilen organizasyonların ortaya çıkmasından sonra da devam etmiştir. ${ }^{1}$

İkinci Dünya Savaşından sonra, devletler bireylere tanınan hakların güvence altına alınması gereğinde görüş birliğine varmışlardır. Bu bağlamda Birleşmiş Milletler Kuruluşunun 1948 yılında yayınladığı “İnsan Hakları Evrensel Bildirgesi” kişi haklarının güvence ve koruma altına alınması açısından önemli bir adım olmuştur. Türkiye'ninde içinde olduğu Birleşmiş Milletlere üye ülkeler bu bildirgeyi onaylayarak, kendi ülkelerinde yaşayan insanlara karşı sorumluluk görevlerini yerine getirmişlerdir. Bildirgenin kabulünden günümüze kadar ki dönemde insan hakları konusunda önemli gelişmeler yaşanmıştır. Bu haklar, kendi içinde, bireysel özgürlük hakları olmak üzere birinci kuşak, sağlık ve sosyal güvence hakları olmak üzere ikinci kuşak ve hasta hakları ile kadın ve çocuk hakları olmak üzere üçüncü kuşak haklar olarak terminolojide yerlerini almışlardır. ${ }^{2,3}$

Tüm dünya ülkeleri 21. yüzyıla girerken ulusal yasalarında hasta hakları ile ilgili düzenlemelere gitmişlerdir. Özellikle Amsterdam Bildirgesi sonrasında, Avrupa kıtasındaki birçok ülke hasta hakları ile ilgili yasal düzenlemelerini gerçekleştirmiştir. Finlandiya 1992 yılında "Hasta Hakları ve Durumu” yasasını kabul ederek, bu konuda öncü rol oynamıştır. ${ }^{1,4}$ Ülkemizde de bu gelişmeler ışı̆̆ında, T.C. Sağlık Bakanlığı tarafından hazırlanan, “Hasta Hakları Yönetmeliği”, 1 Ağustos 1998 tarihinde Resmi Gazetede yayınlanmıştır. 5,6

Hasta hakları, daha iyi sağlık ortamı için hasta ve sağlık çalışanlarının birlikte sahip çıkması gereken haklardır. Konunun önemi ve hukuki sürecin getireceği cezai müeyyideler ile sorumluluklar göz önüne bulundurulduğunda; hem sağlık çalışanları hem de hastaların, hasta hakları kavramı ve yasal mevzuatı bilmesi önem ve öncelik taşımaktadır. ${ }^{7}$

Bu araştırma ile Başkent Üniversitesi Hastanesi ve bağlı sağlık kuruluşlarına başvuran hastalar ve sağlık çalışanlarının hasta hakları konusundaki bilgilerinin, müdahale öncesi ve sonrası düzeylerinin karşılaştırılması amaçlanmıştır.

\section{Gereç ve Yöntem}

Araştırma Ocak 2006 - Temmuz 2007 tarihleri arasında, Başkent Üniversitesi (BÜ) Ankara Hastanesi, B.Ü. Konya Hastanesi, B.Ü. Alanya Hastanesi ve B.Ü. İzmir Zübeyde Hanım Uygulama ve Araştırma Merkezi'nde gerçekleştirilmiştir.

Bu çalışma müdahale tipinde bir epidemiyolojik bir araştırmadır. Müdahale tipi olarak; bir toplumda herhangi bir sağlık sorunun çözmek için sunulacak bir hizmetin (ana-çocuk sağlığı, aile planlaması hizmetleri gibi.) etkililiğini saptamak üzere planlanan ve uygulanan saha hizmet araştırmaları (medical care intervention studies) tipi kullanımıştır. ${ }^{8}$

Araştırmanın evrenini, Başkent Üniversitesi ve bağlı sağlık kuruluşlarındaki sağlık çalışanları ve bu kuruluşlardan hizmet alan hastalar oluşturmaktadır. Sağlık çalışanları meslek ve hizmet birimlerine göre gruplandırılmıştır. Gruplar, hekim biriminden (pratisyen, araştırma görevlisi, uzman, öğretim görevlisi, doçent, profesör), hemşirelik biriminden (hemşire, acil tıp teknikeri, sağlık memuru ve 
teknisyeni), sekreterlik biriminden (sekreter ve hasta danışma) ve ev idaresi biriminden (hasta taşıyıcı, temizlik, posta gibi yardımcı sağlık çalışanları) oluşmaktadır. Hastalar ise, poliklinik ve yataklı hizmet alan olarak ayrılmamış olup, hizmet alan hastaların tümü olacak şekilde evrene dâhil edilmiştir.

Araştırmadaki minimum örneklem sayısı, hasta ve sağlık çalışanları için, evren sayısının bilindiği durumlarda tercih edilen formül yardımı ile hesaplanmış ve formül şekil 1.'de gösterilmiştir.

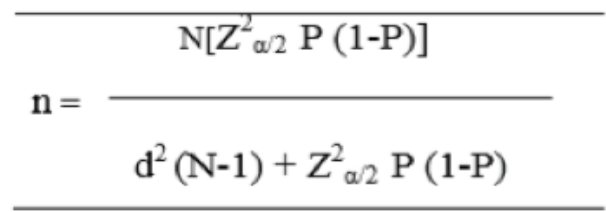

Şekil 1. Evren sayısının bilindiği durumlarda kullanılan örneklem formülü

Araştırmanın örneklem hesabı için, sapma(d) $\pm 0,05, \% 95$ güven aralığında $(1,96)$, hastalar ve sağIık çalışanları için sıklık(p) \%10 olarak kabul edilmiştir. ${ }^{9}, 10$ Merkezlerdeki 2005 yılı aylık yatan hasta ve poliklinik hasta sayılarının ortalaması ve sağık çalışanlarının sayıları (2006 yılı verileri) alınmıştır. Evren ve örneklem sayıları tablo 1'de gösterilmiştir.

\begin{tabular}{|c|c|c|c|c|}
\hline \multirow[b]{2}{*}{ MERKEZLER } & \multicolumn{2}{|c|}{ PERSONEL } & \multicolumn{2}{|c|}{ HASTA } \\
\hline & $\mathrm{N}^{*}$ & $n$ & $\mathrm{~N}^{* *}$ & $n$ \\
\hline Ankara & 1191 & 124 & 22506 & 137 \\
\hline Konya & 392 & 103 & 14095 & 136 \\
\hline Alanya & 287 & 93 & 17602 & 137 \\
\hline İzmir & 74 & 49 & 2392 & 130 \\
\hline Toplam & 1944 & 369 & 56595 & 540 \\
\hline
\end{tabular}

Örneklem yöntemi olarak hastalar için tek aşamalı, sağık çalışanları için ise çok aşamalı tabakalı örneklem yöntemi kullanılmıştır. Sağlık çalışanları için minimum örneklem sayısı hesaplanırken, birinci aşamada, her merkezdeki sağlık çalışanlarının (4 meslek grubunun toplamı) toplam sayılarına göre minimum örneklem sayısı hesaplanmıştır. ikinci aşamada ise, her merkezin kendi içerisindeki sağlık çalışanlarının meslek gruplarına göre (yüzde dağlımları göz önünde bulundurularak) tabaka ağırlığı hesaplanmış, her tabakadan örneğe alınacak sayılar belirlenmiştir.

Araştırmada veri kaynağı olarak anket formları kullanılmıştır. Anket formları sağlık çalışanları ve hastalar için ayrı ayrı hazırlanmıştır. Sağıık çalışanları için hazırlanan anket formunda, 7'si tanımlayıcı özellikleri, 7'si hasta hakları ve mevzuat bilgi düzeyleri, 14'ü hasta haklarına yönelik bilgi düzeyleri ve 15 'i Başkent Üniversitesinde verilen hizmetlerde, hasta haklarının uygulama durum düzeyini belirlemeye yönelik sorular olmak üzere, toplam 43 soru yer almıştır. Hastalar için hazırlanan anket formunda, 9'u tanımlayıcı özellikleri, 7'si hasta hakları ve mevzuat bilgi düzeyleri, 16'sının hasta haklarına yönelik bilgi düzeyleri, 11'i Başkent Üniversitesinde aldıkları hizmetlerde hasta haklarına yönelik uygulama durumunun düzeyini belirlemeye yönelik sorular olmak üzere, toplam 43 soru yer almıştır.
Sakarya Tıp Dergisi 2018;8(3):518-524

ERDEM ve Ark. Hasta ve Sağglik Çalışanlarının, Hasta Hakları Konusunda Bilgi Dúzeyleri: Bir Müdahale Çalışması 


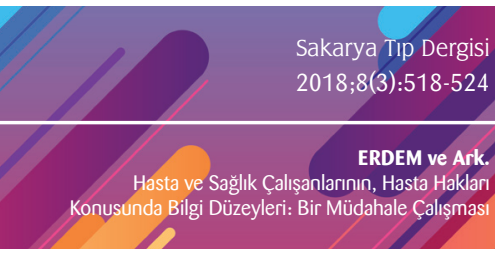

Sakarya Tip Dergis

ERDEM ve Ark.
Bu çalışmada gruplar, grup I müdahale öncesi, grup II müdahale sonrası olarak tanımlanmıştır. Hem hasta hem de sağlık çalışanı anketinde yer alan bilgi sorularında doğru cevaplara 1, yanlış cevaplara 0 puan verilerek her birey için toplam puan hesaplanmıştır. Toplam puan hesaplanırken, sağlık çalışanları için toplam 14 soru (14 puan), hastalar için toplam 16 soru (16 puan) esas alınmıştır. Daha sonra şekil 2.'de belirtilen formül kullanılarak toplam bilgi düzeyi puanları, 100 puanlık ölçeğe dönüştürülmüştür ${ }^{11}$. Böylelikle bilgi düzeyi skorları 100 puan üzerinden personel ve hastalar için hesaplanmıştır.

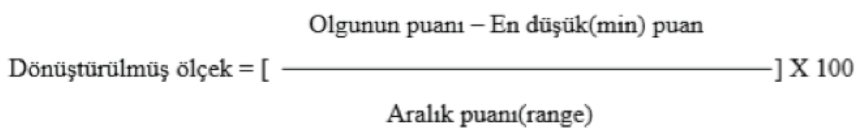

Şekil 2. Bilgi düzeyi skoru formülü̈11

Anket formları aracıllğı ile elde edilen veriler, SPSS (Statistical Package for Social Sciences) for Windows 11.5 istatistik paket programı ile bilgisayara aktarılmış ve analizleri yapılmıştır.

Sağlık çalışanlarının hasta hakları konusundaki "bilgi düzeyi skor puanı” etkileyen faktörler çoklu (multiple) regresyon analizi ile incelenmiştir. Bu analiz için regresyon modelinde bağımlı değişken olarak "bilgi düzeyi skor puanı", bağımsız değişken olarak, öğrenim durumu, hastanede yatarak tedavi alma durumu, grup I ve grup II, meslek grupları alınmıştır.

Sağılık çalışanlarının "hasta hakları yönetmeliğini” okuma durumunu etkileyen faktörler logistik regresyon analizi ile incelenmiş olup; bağımlı değişken olarak "hasta hakları yönetmeliğini" okuma durumu, bağımsız değişken olarak grup I ve grup II, öğrenim durumu, meslek grupları, çalışma süresi analize dâhil edilmiştir. $p<0,05$ değeri istatistiksel açıdan anlamlı sınır olarak kabul edilmiştir.

\section{Bulgular}

Toplam 1240 sağlık çalışanı ve 988 hasta araştırmaya katılmıştır. Araştırmadaki sağlık çalışanlarının \%73,8'i (916 kişi) grup l'i ve \%26,2'si (324 kişi) grup Il'yi oluştururken; hastaların \%58,3’ü (576 kişi) grup l'i ve \%41,7’si (412 kişi) grup Il'yi oluşturmuştur. Örneklem sayıları ele alındığında sağlık çalsşanları için grup I ve grup II'de hesaplanan örneklem sayısının \%100,0'üne ulaşılmış; hastalar içinse grup l'de \%100,0'üne ulaşılırken, grup Il'de \%72,6' sına ulaşılmıştır. Sağlık çalışanlarının yaş ortalaması 28,5 55,7 ve ortancası 27 (en küçük-en büyük:18-58) iken hastaların yaş ortalaması 42,9ะ16,4 ve ortancası 40 (en küçük-en büyük:18-93) olarak bulunmuştur. Araştırmaya katılan tüm hastaların \%31,4'ünü 50 yaş ve üzeri hastalar oluşturmuştur.

İncelenen sağlık çalışanları ve hastaların, hasta hakları ile ilgili bazı önermelere verdikleri "evet" yanıtlarının gruplara göre dağılımları tablo 2.'de sunulmuştur. Önermelere verilen yanıtlar çerçevesinde bilgi düzeyi skoru hesaplanmış ve gruplar arası karşılaşıımalı istatistiksel analizler yapıımıştır. Sağlık çalışanlarının tüm önermelerde grup II de, grup l' e göre evet yanıtlarının artmış olduğu görülmüştür. Sağılık çalışanlarının, hastaların "mahremiyetinin korunması" önermesine grup I de \% 97,1'inin, grup II de \% 99,7'sinin; hastaların "uygulanan tedavinin alternatifleri konusunda bilgilendirilmesi” önermesine, grup I’ de \%95,5'inin, grup II de \%99,0'ının evet yanıtını verdikleri 
görülmüştür (tablo 2.).

Tablo2. İncelenen sağlık çalışanı ve hastaların hasta hakları ile ilgili önermelere verdikleri "evet" yanıtlarının gruplara göre \% dağılımları, 2007

\begin{tabular}{|l|c|c|c|c|}
\hline \multirow{2}{*}{ HASTA HAKLARI iLE İLGiLi ÖNERMELER } & \multicolumn{2}{|c|}{ SAĞLIK ÇALIŞANI } & \multicolumn{2}{c|}{ HASTA } \\
\cline { 2 - 5 } & Grup I \% & Grup II \% & Grup I \% & Grup II \% \\
\hline 1. Hekim ve hemşirelerin ismen tanınması & 89,3 & 93,0 & 87,3 & 90,7 \\
\hline 2. Teşhis ve muayene sonucu bilmesi & 91,3 & 96,8 & 95,7 & 96,8 \\
\hline $\begin{array}{l}\text { 3. Uygulanan tedavinin alternatifleri konusunda bilg- } \\
\text { ilendirilmesi }\end{array}$ & 95,5 & 99,0 & 98,4 & 98,6 \\
\hline 4. Tedaviyi ret edebilmesi & 92,4 & 96,2 & 76,2 & 75,5 \\
\hline 5. Araşırımalara katılımda bilgilendirilmesi & 97,8 & 99,4 & 98,0 & 97,3 \\
\hline 6. Hastalığıyla ilgili sürecini bilmesi & 97,5 & 98,7 & 96,0 & 96,5 \\
\hline 7. Hekimini seçmesi & 93,8 & 98,1 & 92,0 & 93,0 \\
\hline 8. Yakınlarının bilgilendirilmemesini isteme & 92,3 & 95,2 & 87,4 & 83,6 \\
\hline 9. Yaşam desteği hizmetinin kesilmesi & 88,6 & 90,0 & 90,7 & 90,8 \\
\hline 10. Yazılı ve/veya sözlü izin alınması & 93,4 & 97,1 & 93,9 & 96,9 \\
\hline 11. Mahremiyetinin korunması & 97,1 & 99,7 & 96,9 & 98,6 \\
\hline 12. Hakları ile ilgili eğitim alınması & 94,8 & 98,4 & 95,9 & 96,1 \\
\hline 13. Hasta hakları içim birim olması & 95,4 & 98,7 & 97,5 & 95,8 \\
\hline
\end{tabular}

Hastaların en az evet yanıt verdikleri önermenin "tedaviyi ret edebilmesi"(\%76,2), en fazla evet yanit verdikleri önermenin de "uygulanan tedavinin alternatifleri konusunda bilgilendirilmesi" (\%98,6) olduğu saptanmıştır (tablo 2.).

Sağlık çalışanları ve hastaların hasta hakları konusundaki bilgi durumları, gereç yöntem bölümünde belirtildiği üzere 100 puanlık ölçeğe dönüştürülmüş ve hesaplanan puan ortalamaları grup I ve grup II için karşılaştııımışır. Sağlık çalışanları ve hastaların bilgi düzeyi skor ortalamalarının gruplara göre dağılımı tablo 3'de sunulmuştur.

Tablo 3. Sağlık çalışanları ve hastaların bilgi düzeyi skor ortalamalarının gruplara göre dağıımı, 2007

\begin{tabular}{|c|c|c|}
\hline Sağlık Çalışanı & $\begin{array}{c}\text { Ortalama } \pm \text { Standart } \\
\text { Sapma }\end{array}$ & $p^{*}$ \\
\hline Grup I (n=893) & $78,6 \pm 12,4$ & \multirow{2}{*}{$<0,05$} \\
\hline Grup II ( $n=318)$ & $83 \pm 9,50$ & \\
\hline \multicolumn{3}{|l|}{ Hasta } \\
\hline Grup I (n=529) & $72,9 \pm 17,7$ & \multirow{2}{*}{$>0,05$} \\
\hline Grup II ( $\mathrm{n}=388)$ & $73,7 \pm 16,10$ & \\
\hline
\end{tabular}

Sağılık çalışanlarının grup I ve grup Il'deki bilgi düzeyleri skorları karşılaştıııldığında grup Il'de bilgi düzeyi skorlarının grup l’e göre yüksek olduğu (tablo 3 .) ve istatistiksel açıdan anlamlı olduğu saptanmıştır ( $p<0,05)$. Sağlık çalışanlarının hasta hakları konusundaki bilgi düzeyi skor puanlarını etkileyen faktörler çoklu (multiple) regresyon analizi ile değerlendirilmiş ve müdahalenin skoru 4,9 kat etkilemekte olduğu görülmüştür $(p<0,05)$.

Hastaların grup I ve grup Il'deki bilgi düzeyleri skor puanları karşılaştırıldığında grup Il'de bilgi dü-
Sakarya Tıp Dergisi

2018;8(3):518-524

ERDEM ve Ark. Hasta ve Sağglik Çalışanlarııın, Hasta Haklar Konusunda Bilgi Düzeyleri: Bir Müdahale Çalıșması 
Sakarya TIp Dergisi 2018;8(3):518-524 zeyi skorlarının grup l'e göre yüksek bulunduğu fakat istatistiksel açıdan anlamlı bir fark olmadığı saptanmıştır (tablo 3.) ( $p>0,05)$. Grup l'in ortalaması $72,9 \pm 17,7$, grup Il'nin ortalaması $73,7 \pm$ 16,1 olarak hesaplanmıştır.

Sağılık çalışanlarının "yönetmeliği okuma durumlarına" göre grup I ve grup II karşılaştııılığında, grup Il'de sağılık çalışanlarının grup l'e göre okuma düzeyinin fazla olduğu ve istatistiksel açıdan anlamlı farklılık oluşturduğu tespit edilmiştir $(p<0,05)$. Grup I'de sağlık çalışanlarından \%12,6'sı yönetmeliği okurken, grup II'de \%25,2'sinin yönetmeliği okudukları görülmüştür. Sağlık çalışanlarının grup I ve grup Il'de yönetmeliği okuma durumlarının yüzde dağılımları, şekil 3.'de gösterilmiştir. Hastaların "yönetmeliği okuma durumları" gruplara göre değerlendirildiğinde, gruplar arasında istatistiksel açıdan anlamlı farklılık olmadığı görülmüştür ( $p>0,05)$. Grup I'de hastaların \% 8,8'i yönetmeliği okurken, grup Il'de ise \% 6,0' sının yönetmeliği okudukları saptanmıştır.

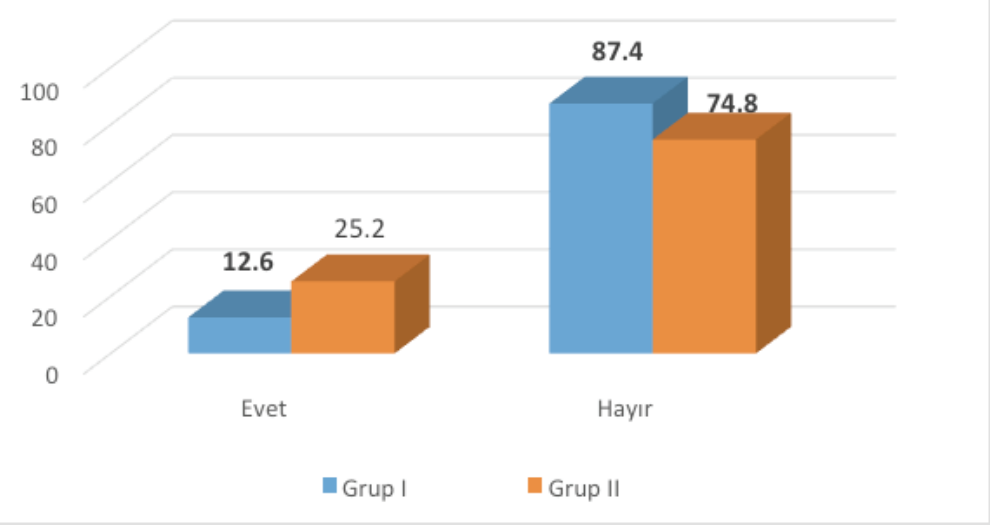

Şekil 3. İncelenen personelin yönetmeliği okuma durumlarının gruplara göre yüzde dağılımları, 2007

\section{Sonuç}

Ülkemizde son 30 yıllık dönemde hasta hakları konusunda önemli gelişmeler yaşanmıştır. T.C. Sağılık Bakanlığı tarafından "Hasta Hakları Yönetmeliği" hazırlanmış ve 01.08.1998 tarih ve 23420 sayılı resmi gazetede yayımlanmış olup 2014 ve 2016 yıllarında değişiklik yapıımıştır.6 Değişiklik ile sağılık kurum ve kuruluşları bünyesinde bulunan hasta iletişim birimleri, "hasta hakları birimine" dönüştürülmüş ve birimlerin etkinliğinin artırılmasına yönelik çalışmalar yapıımıştır. Ayrıca yönetmeliğin hangi usul ve esaslarca uygulanacağına dair, 2014/32 sayılı "hasta hakları uygulamaları genelgesi” Sağlık Bakanlığınca yayımlanmışır. ${ }^{12}$

Hasta haklarının uygulanabilirliğinin artırılabilmesi ve daha nitelikli sağlık hizmetleri için başta sağIık çalışanları ve tüm hastaların (bireylerin) ulusal ve uluslararası mevcut dokümanlardan, yasal mevzuatlardan ve uygulamaların işleyişinden bilgi sahibi olması önemli bir durum olarak karşımıza çıkmaktadır. ${ }^{7}$ Toplumun ve sağlık çalışanlarının bu konudaki farkındalığının artması, aynı zamanda oluşabilecek hukuki sorunlar ve sağıı çalışanlarına şiddetinde azaltılmasına katkı sağlayacaktır.

Araştırma değerlendirildiğinde, ülkemizde hasta hakları ile ilgili yasal düzenlemelerin varlığına rağmen, bu hakların sağlık çalışanları ve hastalar tarafından yeterince bilinmediği görülmektedir. Sağlık çalısanları ve hastaların hasta hakları konusunda bilgi düzeylerinin artırmasında sağlık eğitimleri etkili bir müdahale yöntemi olup, sağlık eğitimlerinin geliştirilerek devamlılığının sağlanması, sürece katkı sağlayacaktır. 
1. Sert G. Hasta hakları uluslararası bildirgeler ve tıp etiği çerçevesinde. 1. baskı. ístanbul: Babil yayınları; 2004.

2. Kapani M. Kamu hürriyetleri. 7.baskı. Ankara: Yetkin Kitapevi; 1993.

3. Doğan BG, Müftü G, Bertan M. İnsan hakları, kadın hakları ve çocuk hakları. Halk sağlğı temel bilgiler. Güler Ç, Akın L. Ankara: Hacettepe Üniver sitesi yayınları; 2006. s:1202-1228.

4. Görkey Ș. Hasta hakları. Medikal etik. Tip organizasyonunda etik ve hukuk. Hatemi H, Doğan H. İstanbul: Yüce yayım; 2002. s:100-126,

5. Güler M. Hekimler ve tabip odası yöneticileri için mevzuat.3. baskı. Türk Tabipler Birliği. 2001.

6. (http://mevzuat.basbakanlik.gov.tr/Metin.Aspx?MevzuatKod=7.5.4847 \&Mevzuatlliski=0\&sourceXmlSearch=hasta\%20haklar\%C4\%B1 Erişim tarihi: :20.06.2018 saat: 15.30 )

7. Özlü T. Hakkınız var çünkü hastasınız. Hasta hakları.1. baskı, i̇stanbul: Timaş yayınları; 2005.
8. Tezcan S. Epidemiyoloji tıbbi araştırmaların yöntem bilimi. Ankara: Hacettepe Halk Sağlığı Vakfı; 1992.

9. Mazıcıŏ̆lu M, Yazııı C, Özer A, Zaimoğlu A. Araștırma görevlilerinin hasta hakları yönetmeliği hakkındaki bilgi düzeyleri. Türkiye klinikleri J Med Ethics 2004; 12: 226-229.

10. Kuzu N,Ergin A, Zencir M. Patients' awareness of their rights in a developing country. Journal of the Royal Institute of Public Health 2006; 120: 290-296.

11. Ware J.E., Snow K, Kosinski M, Gandek B. SF-36 health survey manual and interpretation guide. Lincoln, Rhodelsland: Quality Metric Incorporated; 1993.

12. (https://dosyamerkez.saglik.gov.tr/Eklenti/18878,hhgenelgesipdf.pdf?0 Erişim tarihi: 16.07 .2018 saat: 10.00 ) $\pi$
$>$
2
$z$
$>$
$\pi$
$i$
$D$
$D$

Sakarya Tip Dergisi

2018;8(3):518-524

ERDEM ve Ark.

Hasta ve Sağlik Çalışanlarının, Hasta Hakları

Konusunda Bilgi Düzeyleri: Bir Müdahale Çalışmas 